\title{
The importance of people in the process of converting a narrow tabular hard- rock mine to mechanization
}

\author{
by D. Vogt* and T. Hattingh*
}

\section{Synopsis}

This paper argues that the technology change to mechanization is also going to require a change in people. It presents a model for technological progress and adapts it to the mining industry. It then goes on to motivate the need for mines to become learning organizations in order to achieve maximum value from their people as they become less labour-intensive. In an important sense, mechanization is as much about knowledge as it is about technology.

The change when a mine introduces mechanization or a level of automation is not simply one of technology but also a stage in the development of mining from 'art' to 'science'. 'Art' describes a state of technology characterized by tacit knowledge, an understanding that comes only from experience, and has no formal procedures and little structure. In contrast, 'science' represents a state of technology where all the component processes are understood in detail, all knowledge is explicit, and processes and structures are formal.

Studies of other industries, including metal part manufacture and aviation, show that each stage in the progression from art to science changes the nature of the organization and requires a different mix of skills from the workforce. Perhaps the most important change is the increase in knowledge and decision-making required as the technology gets closer to science.

There is anecdotal evidence that South African underground hard-rock mines are not learning organizations. Mines by their nature are capitalintensive with long lead times from investment to returns, so there is reluctance to change from the original plans or to encourage staff to think independently. Particularly as mines move from art to science, this reluctance must be overcome.

The important lesson for engineers involved in introducing mechanization is to understand that success or failure will be determined by the people involved, and not solely by the technology. The process will almost certainly require a culture change on the mine. We recommend that the mechanization team includes an expert in human and organizational behaviour to ensure that a receptive workforce and management are in place to accept the new technology when it arrives..

\section{Keywords}

levels of technology, mechanization, underground mining, productivity, change management.
Africa announced their intent to mechanize more widely during the first quarter of 2014 and it is now accepted that mining companies in this field will not open new shafts that are not mechanized.

The underground South African coal industry mechanized successfully during the 1970s-1990s from predominantly drill-andblast operations to continuous miners and longwalls. There are now very few drill-andblast sections remaining in the country. Surface mining in South Africa has also followed international best practice, and is highly mechanized.

However, the low stoping heights, modest grades, and difficult dips have slowed the introduction of mechanization in gold and platinum mines, the focus of this paper. Attempts to mechanize in South Africa have met with mixed success. Several gold mines proposed or adopted some level of mechanization in the late 1980s (Association of Mine Managers, 1988), including Joel, Vaal Reefs South, Randfontein Estates, Western Areas, and Freddies. None of those early efforts in gold are today producing by primarily using mechanized methods. Later mechanization efforts concentrated on thicker orebodies at mines like Target and South Deep, and have been more successful.

Mechanization has fared somewhat better in platinum. The lower dip allows the use of rubber-tyred vehicles, and mines have been successful in mechanizing both using mechanized bord-and-pillar and extra-lowprofile methods and by hybrid mining - a combination of conventional layout with machines (Nong, 2010).

* Centre for Mechanized Mining Systems, University of the Witwartersrand, Johannesburg.

(C) The Southern African Institute of Mining and Metallurgy, 2016. ISSN 2225-6253. This paper was first presented at the, 23rd International Symposium on Mine Planning and Equipment Selection (MPES) 2015, 8-11 November 2015, Sandton Convention Centre, Johannesburg, South Africa. 


\section{The importance of people in the process of converting a narrow tabular hard-rock}

Anecdotally, many mechanization efforts fit the model of technology implementation in factories developed by Chew et al. (1991) and illustrated in Figure 1. Planning for the implementation of a new process allows for a delay after the process starts up before the expected improved performance level is reached. In reality, performance actually starts to deteriorate before the change is made, as the factory prepares for the change. Anywhere from weeks to years later, the actual performance returns to its previous level and, with luck, exceeds it. In fact, in many cases, the costs involved in the adjustment period cause the factory to stop the implementation (Chew et al., 1991). The same has happened in many underground narrow-reef hard-rock mines that have attempted to implement mechanization in South Africa.

Chew et al. define the challenge as one of knowledge. If managers knew exactly what problems were going to occur they could anticipate them in advance, but there is a lack of knowledge of the new process, because the experience of current employees is not relevant - this is particularly true when mechanizing a mine. Chew et al. also suggest that managers and engineers do not know in detail what is going on, and that the scientific method is not employed in most manufacturing plants. We argue that the same is true of mining: there are not enough experiments and those that do occur are often not recorded.

In this paper, an existing model for documenting the transition from art- or craft-based activities to those based on science is presented and a variation of the model is proposed for mining. The model highlights how the workplace changes as mining becomes more automated, and therefore how people need to change. It is suggested that South African mines are not learning organizations, and that to succeed in mechanizing, they need to introduce a culture of learning.

\section{Technology development from 'art' to 'science'}

In this section, a general model is described to characterize the level of technology used in an industry. Descriptions of two industries in terms of the model provide the basis for applying the model to mining.

Bohn (2005) describes how technologies develop by invoking the metaphor of transforming from art to science. The metaphor is long established and widely used, for example in the title of an 1802 book on surveying, 'Art without Science, or, The Art of Surveying Unshackled with the Terms and Science of Mathematics, Designed for Farmers' boys' (Sedger, 1802). Today, art and science are seen as ends of a spectrum: 'art' implies a measure of craftsmanship and tacit knowledge that has been passed down from master to apprentice over generations. Each 'artwork' is individual. 'Science' implies a process that uses explicit mathematics and physics to produce predictable, repeatable products.

The maturity of any technology can be described along a number of dimensions. Bohn chose three: how work is done; the quality of results achieved; and how well the technology is understood (Bohn, 2005), tabulated in Table I.

Bohn applied his description of moving from art to science in an analysis of the development of flying (Bohn, 2010). He described how flying started out as a craft, with pilots flying using knowledge laboriously gained, and passed from person to person. By about the 1930s, aircraft had become sufficiently complex that rules and instruments started to be used: knowledge started to become codified. In the 1940s, aircraft became so complex that a level of standardization was required to lower pilot workload, and standard procedures were implemented.

As the science of flying became better understood, it became possible to automate aspects of flying. Today, automated systems are connected together to operate the aircraft, with supervision by the pilot in computer-integrated flight. The key point is that at each stage, the role and nature of the work of the pilot changed until the pilot eventually became a 'manager' of the process of flying.

There is a parallel with the development of the technology of mining: it started as a craft, become subject to rules, and is currently deeply invested in standard operating procedures. As mining becomes more mechanized, the role of the miner becomes similar to that of a modern pilot: managing the process of mining.

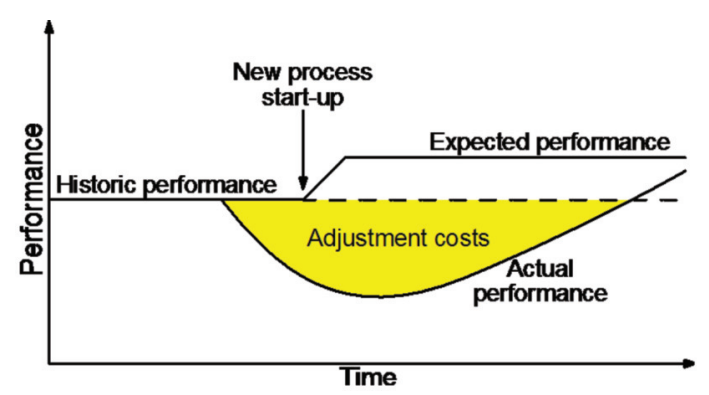

Figure 1-Murphy's Curve. While the details of the curve change, the shape is remarkably consistent (Chew et al., 1991)

Table I

Characterizing technology on the spectrum from 'art' to 'science' (Bohn, 2005)

\begin{tabular}{|l|c|c|}
\hline & Embryonic technology: 'art' & Ideal technology: 'science' \\
\hline How activities are executed & Zero procedure; idiosyncratic & Fully specified procedure \\
\hline What results are achieved & Each one different, mostly poor & Consistent and excellent \\
\hline \multicolumn{2}{|c|}{ Characteristics of knowledge } \\
\hline How knowledge is specified & Purely know-how & Codified \\
\hline What is knowledge about & Minimal, can distinguish good from bad results, but little more & Also know-why \\
\hline Extent of knowledge & & Complete \\
\hline
\end{tabular}




\section{The importance of people in the process of converting a narrow tabular hard-rock}

Bohn's dimensions of art and technology in Table I describe some measures that can be used to qualitatively investigate the maturity of the technology in a particular mine or mining method, but they leave much to be interpreted. It is also difficult to draw a parallel with flying, given the small number of pilots on aircraft and the large number of miners in a mine. A more explicit, though not direct comparison for mining can be made by comparing it with a well-characterized existing process. In the next section, a study of metal parts manufacturing is summarized as a framework to suggest an analogy for the mining industry.

\section{A case study of technology development: gun manufacture}

Beretta manufactures guns in northern Italy. It has operated since 1492, has a continuous record of its activities dating back to 1526 , has been owned by the same family for 16 generations, and has survived six revolutionary transformations in metal part manufacturing. Beretta is an excellent case study in manufacturing technology because its product, guns, has remained constant for more than five hundred years, while the process of manufacturing the product has changed dramatically (Jaikumar, 2005).

Jaikumar's study (2005) is summarized here for the insights it can offer into the similar technological change occurring in mining. His paper is well worth reading for its complete description of many of the aspects of technology change and manufacturing, only some of which are summarized here.

\section{The Craft System}

When Beretta was established, guns were manufactured using the Craft System. Craftsmen made each part of the lock of a gun using a forge and files, and by continuously comparing the part being made with a reference model kept in the workshop. Each part was then adapted to fit with the parts that had already been manufactured, until the lock was complete. The people in the lock shop were product-focused, with everyone involved in all processes. The degree of skill of the worker had a huge effect on productivity, with the most skilled workers being up to four times more productive than the least skilled (Jaikumar, 2005). A master managed a workshop of about eight people and passed his craft on to journeymen, who in turn aspired to become masters through a process of learning. Everyone in the shop was skilled and adaptable. Adaptability was required because of the inability of the process to create accurate, precise, and repeatable parts (Jaikumar, 2005).

\section{The English System}

In about 1810, Beretta introduced the English System. From about the 1790s, machine tools were being introduced in Britain. Two innovations allowed the English System to become dominant: the machine lathe and the micrometer (Jaikumar, 2005). These two tools allowed gun part manufacture to become less labour-intensive and, for the first time, they allowed for parts to be made according to an engineering drawing. The master in the workshop was no longer required to provide guidance or approval: drawings gave guidance and a micrometer ensured that a part complied with its specification. Workers were no longer productspecific, but became experts on particular tools.

In this paper, productivity is taken to be the number of guns made per employee and the minimum effective scale is the smallest group that can economically produce a particular set of parts.

The English System improved productivity over the Craft System about fourfold, but at the same time, it increased the minimum scale of a workgroup from eight craftsmen to about 40 people using three machines. In the English System, all workers were still directly involved in making products (Jaikumar, 2005) and there was a formal system of learning, though now of trades rather than components.

\section{The American System}

The availability of skilled operators became a constraint on growth. The American System was designed to overcome this limit. It was introduced at Beretta in 1860 through the purchase of a factory from Pratt and Whitney (Jaikumar, 2005). The American System was developed to provide precise and interchangeable parts. In the English System, parts were made to fit with one another as closely as possible, and were not interchangeable. In the American System, parts could be interchanged easily by being designed for clearance (Jaikumar, 2005). Charles Babbage was the first person to characterize the advance of the American System over the English by using the word 'manufacture' rather than 'make' to describe the process (Balconi, 2002).

In practice, the American System introduced the idea of a factory as a large machine for making a product. The American System divided the manufacture of each part into a number of processes, and assigned each process to one operator using one machine. Each machine was designed only to apply a single operation to the part. Go/no-go gauges determined if a part met specification.

The American System started the shift towards unskilled labour on the production line. Operations were codified so that new operators could be trained with an absolute minimum of effort. It was also during the introduction of the American System that the workforce stopped being 100\% devoted to production. Now, there were workers who built, maintained, and improved machines, and others made parts by the thousand. The minimum scale of a factory increased to about 150 people, where 20 of those were not directly working in production. Productivity per person increased by about threefold over the English System (Jaikumar, 2005). It is also likely that the labour cost per gun produced went down due to the lower number of skilled workers.

\section{The Taylor System}

If the factory was the machine, the next step in technological advancement was to apply the principles of science to the workers. Frederick Taylor realized that workers were not making maximum use of machines, and productivity could be improved if human activity was measured, analysed, and then controlled in the manner that machine work was controlled in the American System (Jaikumar, 2005).

Taylor broke each job down into its smallest elements, and measured the effort required for each. He also separated activities: for example, a lathe operator might find that his cutting tool needed sharpening. In earlier times, the lathe 


\section{The importance of people in the process of converting a narrow tabular hard-rock}

operator would have sharpened the tool himself. Taylor considered sharpening to be a different activity to cutting and separated the tasks. He measured how long each task took through time study and he standardized the machines to achieve high utilization.

At Beretta, where it was introduced in 1928, the Taylor System resulted in a threefold increase in productivity over the American System, but increased the minimum scale of a factory to 300 people operating 150 machines. Of the workforce, 60 were involved in maintaining the factory and in quality control (Jaikumar, 2005). As in the American System, the bulk of workers were unskilled, with a small group of highly skilled workers who maintained the factory, planned new products, and developed the procedures used by the rest of the staff. The Taylor System represents the lowest point of worker involvement with the whole process as the workers on the line had no concept of the product beyond their own small tasks.

\section{Statistical process control}

In 1950, Beretta started producing its own machine tools as a result of a contract to produce a new rifle, the Garand M1, for NATO. The contract specified tolerances an order of magnitude tighter than they had previously achieved, and interchangeability of components had to be $100 \%$ (Jaikumar, 2005).

In order to achieve high accuracy and precision, the variability in factory processes had to be accounted for and removed. This was done through the introduction of statistical process control (SPC). While Taylorism is based on the idea of a 'right' or 'best' way to conduct a machining operation, machines do not perform consistently. The Taylor way will not produce identical parts, for example, as a lathe tool loses its sharpness.

To counter variations in the process, Beretta started visually recording key parameters of parts on charts as they were manufactured. The charts allowed the operator to identify systematic error and compensate for it. Day-to-day management now focused on the process, rather than the products (Jaikumar, 2005). At the same time, automation reduced the labour required for manufacture, which freed operator time to monitor processes and identify and solve problems.

Under SPC, quality control became an integral part of manufacture. The staff function increased from 60 to 100 people, while people with a line function decreased from 240 to 200 . Overall, the minimum scale of 300 people and 150 machines remained.

SPC reduced rework from $25 \%$ to $8 \%$, but productivity increased only by between $25 \%$ and $50 \%$. So was SPC a revolution? Jaikumar argues that it was, as the nature of work changed. Operators became managers of the process, with a requirement for learning, discretion, and control of work that had been removed by the American and Taylor systems (Jaikumar, 2005).

\section{Numeric control}

SPC was the first process that recognized the difference between information about the process parameters and information about the physical process itself. This realization was taken further with the introduction of numeric control (NC), later to become computer numeric control or CNC.
$\mathrm{NC}$ allowed a general-purpose machine to undertake a number of operations on a single part. The major difference between NC and previous semi-automated machines was the ability to easily alter the operations by changing the programming on $\mathrm{NC}$ machines.

For NC to work at high production rates, every element of the machining operation has to be made explicit. Knowledge held by machinists, for example about adjusting tools as they wear, now has to become codified.

CNC greatly reduces the manual set-up time so a single operator can now look after more than one NC machine. One operator and a group of machines becomes a cell, leading to a cellular plant layout (Jaikumar, 2005).

An NC operator now becomes concerned not with a process, but with a procedure. NC at Beretta improved productivity threefold over SPC, but significantly, it dropped the minimum scale from 300 people running 150 machines to 100 people running 50 machines. Only half of the people were directly involved in production, although the tasks undertaken on the line blurred the definition of 'line' versus 'staff'. NC greatly improved the flexibility of the line too, allowing a single line to produce up to 100 different products with just a $2 \%$ rework rate (Jaikumar, 2005).

The change to NC was significant and difficult. Jaikumar (2005) reports “"It was," averred Ugo Beretta, "the biggest change in the culture of the plant that I have ever seen." But it added a flexibility and standardization that was of huge benefit. In 1985, Beretta won the contract to supply the standard pistol for the US military, but the weapon had to be manufactured in the USA. The reproducibility and transportability of NC methods meant that Beretta could build a new factory in the USA in less than eighteen months, and make money despite their bid being less than half that of the next cheapest bidder.

\section{Computer-integrated manufacturing}

For Beretta, the next move after NC was to computerize the entire manufacturing process, including design and factory operation, in what became known as computer-integrated manufacturing (CIM). CIM at Beretta started with a flexible manufacturing system (FMS) that consisted of a number of NC machines serviced by an automatic belt and robot arms for loading and unloading. In a typical line at Beretta, three machines perform all the operations to manufacture a receiver (part of a gun) and are managed by a single worker.

The flexibility reduces the minimum viable scale to just 30 people, with 20 of them in staff functions, and 10 operators managing 30 machines. CIM offers a threefold improvement in productivity over $\mathrm{NC}$, and a remarkably low rework rate of just $0.5 \%$ (Jaikumar, 2005). The flexibility also offers the potential of manufacturing any product that can be designed, one day potentially leading to production runs of just a single custom gun.

Jaikumar (2005) makes the point that CIM started off as a productivity enhancement tool, but it quickly became apparent that it is also a knowledge enhancement or learning tool. It encapsulates knowledge about processes, and adds to that knowledge with each new product. It also provides a level of system intelligence by integrated problem-solving over different areas in the factory, rather than concentrating on single functional or product areas. 


\section{The importance of people in the process of converting a narrow tabular hard-rock}

\section{Summary}

Jaikumar's study discussed the evolution of manufacturing using at least sixteen different factors. Four key factors are summarized here: productivity, minimum effective scale, the ratio of line to staff functions, and decision-making freedom on the line.

In Figure 2, the productivity improvement as a result of each technology change is plotted. Other data (Jaikumar, 2005) shows that each technology change resulted in a step change in productivity, and that between step changes there was little organic improvement in productivity.

In Figure 3, the blue graph plots the number of people required to achieve a workable scale. In the craft era, it was eight. In a modern CIM factory, it is 30 . In between, it went up as high as 300 in the time of the Taylor System and SPC.

The red line in Figure 3 illustrates the percentage of people working in the factory actually making parts. In the Craft and English systems, everyone was making parts. With time, the overhead for maintenance, quality, and planning increased, until in the CIM age, only one-third of employees were directly operating machines.

Although the percentage of workers on the line decreases, Figure 4 shows that modern line workers have similar levels of flexibility in decision-making as those in the Craft System. The figure also implies that the need for learning in the workforce has increased since the Taylor era.

\section{What mining can learn from gun manufacture}

At a time when mining companies are desperately searching for improvement in productivity, experience at Beretta suggests that large increases are not going to come from organic improvements in productivity, but through a step change in technology.

As technology changes, the nature of work in mining is going to change. As gunmaking moved from art to science, the number of people employed first rose, then fell dramatically. We saw the rise in worker numbers in the early years of the South African gold mines. As mechanization is implemented, numbers will fall.

At the same time, the skills mix will change. At the science end of the Beretta example (Figure 3), the fraction of operators in the floor as a percentage of overall staff has fallen. As mechanization is implemented, while operator numbers will fall, there will be an increasing demand for skilled professionals in indirect roles such as mine design, operations planning, ventilation, and rock mechanics, to support the rapid rate of mining enabled by mechanization.

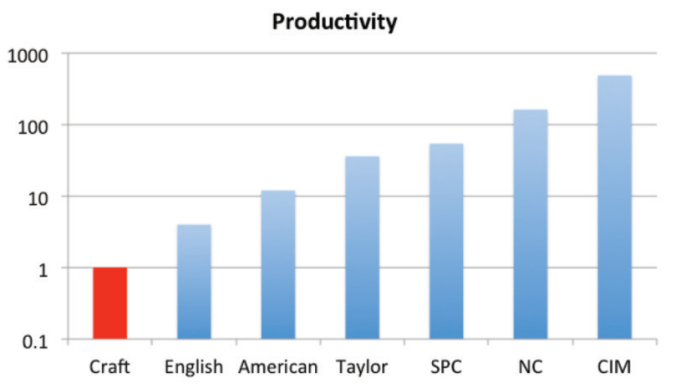

Figure 2-Productivity improvements by technology change
At the same time, the operators themselves will have greater flexibility of decision-making (Figure 4), and will be expected to use this flexibility. The current culture in mining in South Africa does not promote a high level of autonomy in operators, or more generally. A culture change will be required.

The level of change management required should also not be underestimated. Beretta's comment that the change to $\mathrm{NC}$ was the biggest change to the culture of the plant that he had ever seen is equally applicable to the change to mechanization in narrow-reef mining. Moxham (2004) cited change management as an unresolved issue for mechanization, and it remains so today.

\section{Mapping mining from 'art' to 'science'}

By analogy to the manufacturing example, it is possible to map mining on a scale from art to science. There are different ways of marking out epochs in mining, for example Karmis et al., (2010) describe how mining engineering education has changed with time. Another typical mapping is of the technologies involved, moving from conventional to fully automated. Here a mapping is developed that aligns with the epochs described for manufacturing in Jaikumar (2005), focusing on the nature of the work experience: the autonomy of the operators, the knowledge required to do the job, and the need for learning,

The focus on the operators and on their knowledge requirements shows the importance of people, learning, and knowledge for the introduction of mechanization.

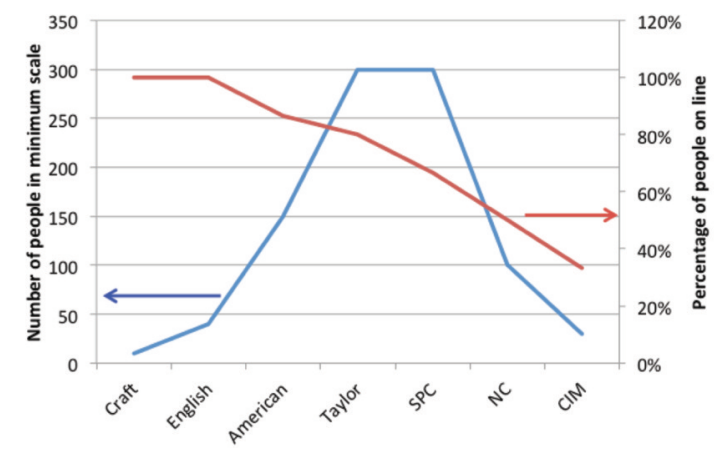

Figure 3-Number of people in minimum effective scale, and percentage of workers engaged in line functions

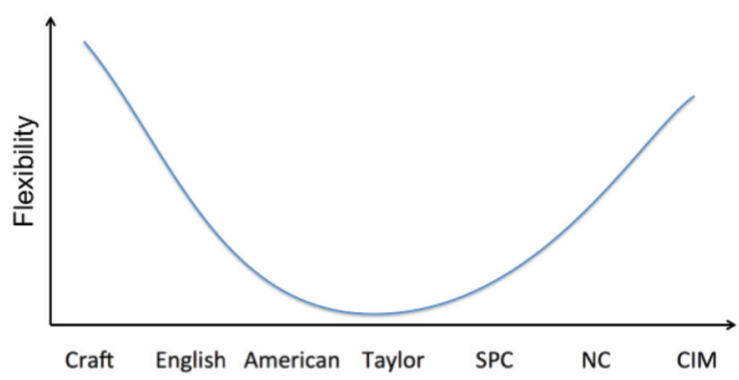

Figure 4-Schematic of decision-making flexibility on the line in the various technological epochs 


\section{The importance of people in the process of converting a narrow tabular hard-rock}

\section{The craft epoch}

The craft epoch of mining is epitomized by the descriptions in 'De Re Metallica', the famous book on the state-of-the-art as it was in the mid-16th century, written by Georg Agricola (Hoover and Hoover, 1950).

At the time, metal implements were used to break rock, typically hammers and chisels; or fire was used to flake off pieces of rock, today known as thermal spalling. Agricola paints a picture of relatively small groups of people working together. Of their leader, the miner, he says 'For a miner must have the greatest skill in his work.' Agricola goes on to list the skills required of a miner, including knowledge of geology, mine design, assaying, metallurgy, 'philosophy' (what we would call the scientific method), medicine, astronomy, surveying, arithmetic, architecture ('that he himself may construct the various machines and timber work required underground'), drawing, and law (Hoover and Hoover, 1950, bk. 1). The list is not that different from a modern mining curriculum.

According to Bohn's description in Table I, mining of this period is typical of the craft state of knowledge. Miners had extensive knowledge of 'what', but not of 'why' in the sense that they did not understand much of the underlying science of what they did. They understood the entire process and they were open to learning. In the same way as in Jaikumar's craft epoch in industry, they also passed knowledge from person to person and knowledge was largely tacit. The miners were responsible for their own performance in the sense that they knew how to follow veins, how to mine them safely, and how to extract the metal for profit.

Two key technologies came to the craft epoch in the second half of the nineteenth century: dynamite and drilling machines. Early attempts to use gunpowder for rock-breaking quickly led to placing it in a hole drilled in the face. The pneumatic drill, patented by Ingersoll in 1871 (Mahmud, 2012) greatly increased the speed of drilling, and with the introduction of dynamite in 1867 the technology was in place to allow high productivity within a craft environment. The technology itself did not change the nature of the work: craft miners still understood the whole process and still valued learning.

There is evidence of the craft skills of Cornish miners in early South African gold mines: the quality of early excavations shows deep understanding of mining techniques. The Cornish were prized as miners precisely because of their skills, passed down from father to son, or through fellow workers (Hovis and Mouat, 1996).

But the large scale and low grades of the Witwatersrand orebodies led to a need for mining on a massive scale and with it, the demise of the craft miner.

\section{The labour-intensive epoch}

When a mining operation has low grades and high capital costs, it is economical to mine only on a large scale. The early Witwatersrand goldfields were an example. Sinking shafts was expensive, and once the early shallow claims had been mined out, mines had to increase their production to cover the costs of their shafts and other development. They did this by greatly increasing their scale, exactly as gun-making had done in the move to the American System not many years before.
By 1910, there were already more than 200000 people employed on Witwatersrand gold mines, of whom 20000 were white (Wilson, 1972). Because of colour-based job reservation (Wilson, 1972) the ratio of white to black workers at this time is a proxy for the ratio of skilled to unskilled workers.

The epoch of labour intensity is also one of lower skills, matching the American System in the gun industry described earlier. Mines started work-study activities, and went on to implement Taylorist management. A study of mining in the western USA (Hovis and Mouat, 1996) at around the same time as the early Witwatersrand (1896-1930) shows that those mines were following a similar trend, becoming much larger, controlled by mining engineers and metallurgists, with a lesser role played by skilled miners. The picture is of many unskilled workers in a large undertaking, managed by experts. Each individual worker is unskilled, and does not see or understand the whole process of mining.

Labour intensity led to high costs associated with labour, which caused industrial relations problems on several occasions on the Witwatersrand, most famously in 1922 and in 1989, but more recently in 2014 when most major South African platinum producers suffered a five-month strike caused by a demand for higher wages. One way around the impasse of high wage costs and low commodity prices is to mechanize.

\section{Mechanization}

Replacing human muscles with machines as a source of power increases the power available and hence the extraction rate. Nowhere in mining is this better demonstrated than the longwall mining system in a colliery, where just a handful of operators could already mine nearly a million tons of coal per month in the late 1990s (Kingshott and Graham 1998).

Machines can also remove people from areas of highest risk, making mines safer.

The required change in the nature of work in the move to mechanization underground is comparable to the changes that occurred in the statistical process control and NC epochs in manufacturing mentioned above:

- Workers become more productive

- For each machine, there is an increasing group of support people. A typical continuous miner may require one artisan for two machines, with further artisans employed in maintenance, and professionals employed to plan and manage operations

- A miner has more freedom to make decisions about how to execute work, although still within a framework of standard operating procedures (SOPs)

> The decisions taken by an individual miner start to have a material influence on the performance of the whole mine.

The epoch of mechanization is characterized by a move toward science: knowledge is becoming increasingly codified, procedures are becoming specified, and results can be consistent and excellent. The extent of knowledge has grown.

The largest area of discrepancy between many mechanized operations and a 'science' as defined by Bohn is in the nature of knowledge: there is often still a gap in the knowledge of operators about why they are undertaking 


\section{The importance of people in the process of converting a narrow tabular hard-rock}

certain operations. There is also a gap in valuing knowledge and consciously making use of experience and experiments to learn and gain new knowledge.

\section{Automation}

Automation is defined here as mechanized equipment operating independent of human control at some level. There is limited automation in mining already, particularly in trucks. In high-wage countries with mines in remote locations, an automated truck can offer a considerable cost saving over a truck that requires drivers. In 2013, Rio Tinto announced that its automated trucks had moved $100 \mathrm{Mt}$ of rock in Australia (Validakis, 2013).

There are also automated systems running underground. Among others, De Beers implemented a truck loop on its Finsch mine in 2005 (Burger, 2006), and plans automated tramming in the block cave level of its Venetia mine. An advanced automated system is operating at Kiruna in Sweden (Paraszczak and Planeta, 2001).

The level of automation varies from driver assistance, through remote tele-operation with driver assistance, to full automation. Apart from removing the driver, automation extends the benefits of mechanization and improves productivity, improves the quality of the excavation, and reduces operating and maintenance costs because the machines are always operated within their design limits (Brouillette et al., 2003; Paraszczak and Planeta, 2001; Swart et al., 2002).

Possibly the biggest saving to be gained through automation is by making roadways narrower. Automated trucks can navigate so accurately that they can safely pass each other with less space between them, so roads can be narrower and correspondingly cheaper to build (Bellamy and Pravica, 2011).

Automation occurs at a high level on the art-science continuum. In addition to the requirements for an operator in a mechanized system, operators of automated systems require knowledge of why operations occur as well as how. Much of the knowledge is already codified within the computer programs that operate the machines, much as it is in automated flying or NC control in factories.

While independent machines have been automated, the next phase, of automating fleets of equipment, is just starting to be investigated.

\section{Computer-integrated mining}

Beyond automation, there is much to be gained by optimizing the entire process of mining, from exploration to product (Miller, 2009). Mines are traditionally managed using compartmentalized systems, with each activity optimizing its own operations, independent of the needs of the larger system. Modern information technology systems are making it possible to monitor and control the entire value chain within the mine to optimize chosen metrics such as cost, productivity, or capital expenditure.

A fully automated mine with computer integration would have few operators in the traditional sense. Those operators would be knowledgeable about their own tasks and the broader context of the entire process. The majority of people employed on the mine would be involved in maintaining the machinery (artisans), and in planning and executing the construction and operation of the mine (geologists, mining engineers, electrical, mechanical, and industrial engineers, etc.).

\section{Implications for mining}

The five stages of mining listed here describe the type of people required in each phase, and can be used as a guideline to what will be required from the workforce when mechanization is implemented.

The literature from other sectors that have mechanized is useful because it can prepare miners for the inevitable steps and challenges at higher levels of technology. While solutions for some steps are self-evident, such as the need for more skilled artisans, thinking about how jobs change can speed the transition. It is clear that workers in automated factories are expected to think differently, and have a more holistic view of the operation. We argue that this expectation is still missing in most thinking about mine mechanization.

\section{The need for a learning organization in mining}

The changes in the level of discretion or autonomy, required knowledge, and individual productivity as mining moves from art to science require new thinking from everyone working on the mine. The step from massive labour-intensive mining to mechanized mining is particularly challenging. Changed thinking is intimately associated with learning. Learning organizations, discussed here, provide environments that enable the learning necessary to adapt to new techniques like mechanization.

Comparisons of mining with technological epochs in other industries show the need for workers who are able to learn and organizations that encourage and facilitate learning. Are mines currently learning organizations?

There are many lines of evidence that South African narrow tabular hard-rock mines are not learning organizations. As one senior technical consultant to the industry recounted, 'When I started on the mines I learnt two things: how to lie and how to keep out of sight.' The statement typifies the culture: results-driven and authoritarian.

The discussion in this section is anecdotal, based on informal discussions over many years with mining professionals and others who work underground.

\section{Student thinking}

Initial evidence of the constraints on thinking comes from students. The University of the Witwatersrand offers courses as one of the components of a Master's degree in mining. On one 2015 course, the student attendance was split roughly 50:50 between students who had come straight from their undergraduate studies and students who were working in mining and studying part time.

There was a notable division between the two groups of students because of the constraints on creativity demonstrated by the students with work experience. While any change to improve mining productivity ultimately has to be practical, the work experience of these students had limited their ability to even consider approaches outside of the current norm.

\section{Change in Bushveld Complex mines}

Miners in the platinum sector have often commented on the relative ease of introducing new technology on the eastern 


\section{The importance of people in the process of converting a narrow tabular hard-rock}

limb of the Bushveld Complex compared with the western limb. Miners on the eastern limb are usually from local communities, with no previous history of mining. Mine managers are able to implement novel practices, because the miners don't know any other way of doing things.

Miners on the western limb often come from the Witwatersrand gold mines, or have long histories in mining. Attempts to change practices on the western limb have run into problems, with miners simply reverting to previous practices.

The unwillingness to learn on the western limb is indicative of the lack of a learning culture: the miners have preconceived ideas and have no desire to learn new ones. Miners on the eastern limb have no choice but to learn, as they have no prior experience. Companies can introduce new techniques because the workforce is willing to learn. The evidence does not indicate that eastern limb workers have a learning culture and will retain it in the future, but does explain part of why mechanization has been more successful on the eastern limb.

\section{Information flow}

Compliance with the results-driven and authoritarian culture is exacerbated by a lack of timely management information about the state of operations underground. On deep gold and platinum mines, many key operating parameters such as face advance are measured only once a month. The low sampling rate makes it possible to get away with a lie like, 'Yes sir, I did blast today'. The miner hopes to compensate for the lie with greater productivity before the measurement date and the manager is not easily able to check the truth of the statement.

This lack of timely information, combined with a relatively simple layout and very large workforce, has been managed through a strongly hierarchical system. The system has applied typically bureaucratic methods, including standard operating procedures. It is seldom that a mine dynamically adapts its SOPs or plans to cater for changing geological conditions. Miners underground are not asked to learn and are discouraged from challenging their superiors, the current processes, or practices. Miners are also expected to function only within their own trade, such as drilling, and not to understand or even ask questions about the broader priorities of the workplace.

\section{Mining priorities}

Production is the key priority in mines. Even with the recent focus on safety, it is widely understood that production is still the priority. Mineworkers in South Africa earn a large percentage of their packages through production bonuses. They regard any threat to production as an imminent threat to their livelihoods. It is challenging to introduce a new technology when there might be a short-term drop in production prior to a long-term increase - people are not interested in the delay that will be caused by the learning process.

\section{The learning organization}

Peter Senge promoted the idea of a learning organization in his book 'The Fifth Discipline', subtitled 'The art and practice of the learning organisation', (Senge, 2006). Senge defines learning organizations as 'organizations where people continually expand their capacity to create the results they truly desire, where new and expansive patterns of thinking are nurtured, where collective aspiration is set free, and where people are continually learning to see the whole together'. Senge believes that 'in the long run, the only sustainable source of competitive edge is your organisation's ability to learn faster than its competitors.' (Senge, 2006).

The idea of the learning organization is also intrinsic to one successful school of thought about manufacturing. Toyota Motor Corporation emerged to become the largest car manufacturer in the world on the basis of its Toyota Production System (TPS), also known as Lean Manufacturing or just Lean (Womack and Jones, 2003). Ballé et al., (2006) argue that four frames pervade the TPS: "performance mindset, problem awareness, solving problems the "right" way, and developing people through problem-solving'. All but the first frame are associated with creating an environment that allows and encourages learning in order to solve problems.

Within a context of core capabilities, Leonard-Barton (1992) discusses how she observed four responses to proposed technological change in manufacturing plants. All are a consequence of people: abandonment; recidivism; reorientation; and isolation. The first two lead to failure, the last two are routes to success:

> In the case of mining, abandonment and recidivism both lead to mechanization not being applied: either the new technology is abandoned, or the workers go back to their old ways - in other words, it might be a mechanized mine, but it looks and operates like a labour-intensive mine. Abandonment of mechanization is often a consequence of a lack of preparedness (Nong and Musingwini, 2011), which may stem from insufficient emphasis on change management

- Reorientation refers to relocating a change project into a group without the same core capabilities as the original group. In mining, it could refer to using a new team to implement mechanization that does not share key core capabilities, particularly in managerial systems and values, with the original team

- Isolation occurs in new product development when development is undertaken in a new plant. Isolation is related to reorientation, but refers to adopting a new technology in a different place, rather than with different people. In mining, it suggests that mechanizing a new mine is easier than mechanizing an existing one, not least because the people employed on a new mine would not share the managerial systems and values of an existing mine.

\section{What we can learn for mechanization}

Returning to Murphy's Curve, the case study that started this paper (Figure 1), Chew et al. (1991) offer some recommendations on how to make a successful technological transition. The recommendations are both people- and process-related and are adapted here for a mechanized mining context.

> Think of implementation as research and development. If mechanization is seen as something that can just be purchased and put into operation, then the implementation programme will be planned in that way. Instead, 


\section{The importance of people in the process of converting a narrow tabular hard-rock}

the introduction of mechanization should be seen as an experiment. There will be successive phases of data gathering and learning through experiment as the implementation moves through the scoping, prefeasibility, and feasibility stages before being implemented. The goal of experiments should be to address technical and organizational uncertainty. Miners need to be part of the team, working as codevelopers, rather than having the system dumped on them

> Ask 'what made it hard', not 'how well did it work'? Miners do look at other mines before implementing mechanization, but the conversation is often about the success. To learn more about the challenges, it is necessary to dig into them with questions like "how did you make this work? What had to be changed? What would you do differently?' (Chew et al., 1991). Miners should also look at parallel experiences in other industries. As this paper makes clear, the manufacturing industry has a lot of knowledge about mechanization available for miners to consider

Learn in many ways at once. There are generally four methods that a mine could use:

- Vicarious learning - watch what others are doing and learn from them

- Simulation - construct synthetic models and use them for experimentation and learning

- Prototype - build and operate the proposed system on a small scale and in a controlled space

- Production, or on-line, learning - learn while trialling or operating the final product (Chew et al., 1991).

As we move down the list, the cost goes up and the scope for experimentation goes down. According to Chew et al. (1991) managers prefer the perfect fidelity of the operating system (by definition it matches reality perfectly), failing to recognize that learning is not all or nothing - there is value in learning about single key issues using tools with less fidelity, which leads naturally to:

Simulate and prototype everything. If production learning is expensive and restrictive, and vicarious learning is limited, simulation and prototyping are critical. Simulation can vary from spreadsheets to physical models of a mine. It allows for easy investigation of complex systems, where individual components are understood, but the way they interact is not. It is easy and cheap to run many simulations to investigate each component of a proposed mining system.

In manufacturing, a prototype is a physical simulation of a process. For mining, a prototype is a trial area. For best value, the trial should be conducted with the purpose of improving the process, rather than just as a method of training people to comply with the process

> 'Everything' includes the organization. If the rule is 'simulate everything', then everything must include the organization. The physical processes of a new mining layout, for example, are often simulated (Valicek et al., 2012). There is much to be gained by also simulating the organizational structure and culture of the proposed new system.
- Be prepared, but not too prepared. As the military strategist von Moltke said 'No battle plan survives first contact with the enemy.' Implementation failures, particularly in mining, are often blamed on poor planning. Plans are often too specific and end up being unable to deal with reality. It is better to have a clear goal, and prepare for contingencies by having resources and good people. The plan should focus on what to look out for and think about, rather than what to do (Chew et al., 1991)

> Produce two outputs: ore and knowledge. Once a new mining method is up and running, problems will still arise. If the need to produce knowledge is explicitly recognised as part of production, that knowledge will lead to faster problem-solving. This recommendation from Chew et al. follows the philosophy of Lean (Ballé et al., 2006). The most expensive time to learn is once the mine is running - but it is still better in the long run to take the short-term cost of learning in exchange for the long-term gain in operational performance.

Chew et al. argue for the need to plan and manage directed learning, 'Anything you don't learn about early will hurt you later.' They criticize typical investment analysis that sees learning as a pure cost and recommend budgeting for learning throughout the project schedule. In particular, there needs to be budget for learning on the operating system in the first few months of operation, over and above the planned lower output during start-up. If the earlier learning stages of vicarious learning, simulation, and prototyping have been thoroughly used, $10 \%$ of production time is realistic (Chew et al., 1991).

\section{Conclusion and recommendations}

Mechanizing a mine requires a change in technology, but it also creates a change in the nature of work for the miner. Experience in manufacturing shows that there is high resistance to changes in the nature of work, particularly when the change requires people to accept higher levels of decision-making and responsibility. There is also a need for employees to better understand the overall process as mining moves from art to science.

It is much easier to implement change in a learning organization. Anecdotal evidence shows that mining companies in South Africa are not learning organizations, but are still organized along Taylorist principles. Taylor's thinking has been superseded with the recognition that the circumstances of an operation change with time.

In an environment that is as subject to variability as the rock in an underground mine, a mechanized mining approach requires a management system that allows for higher levels of personal initiative. Such a learning system would improve conventional mining operations, but it is essential for a successful shift to mechanization.

\section{Specific recommendations}

Given that engineers drive most mechanization projects, we recommend that mechanization teams incorporate experts in human and organizational behaviour to ensure that the people issues discussed here are not neglected during the planning and execution of the project. 


\section{The importance of people in the process of converting a narrow tabular hard-rock}

Consider approaches to mechanization that allow for learning, such as trial sites, mechanizing on new mines, or using teams from different backgrounds to the conventional miners on your mine. Allow reorientation and isolation to work for you in the change process.

Use simulation. It is much cheaper than physical trials, it is getting rapidly more comprehensive, and it can help ask and answer questions about organizational issues that won't occur during small-scale prototype tests.

Think about implementing mechanization as a quest for knowledge as well as rock, and budget for experiments. If generating knowledge is incorporated into the planning from the start, it will not come as a surprise when experiments need to be conducted to determine parameters that weren't planned for.

\section{References}

Association of Mine Managers of South Africa. 1988. Trackless Mining Symposium 1988. Chamber of Mines of South Africa, Johannesburg.

BaLconi, M. 2002. Tacitness, codification of technological knowledge and the organisation of industry. Resources Policy, vol. 31. pp. 357-379.

Ballé, M., Beaufallet, G., Smalley, A., and Sobek, D. 2006. The thinking production system. Reflections, vol. 7. pp. 1-14.

Bellamy, D. and Pravica, L. 2011. Assessing the impact of driverless haul trucks in Australian surface mining. Resources Policy, vol. 36. pp. 149-158.

BoHN, R. 2005. From art to science in manufacturing: the evolution of technological knowledge. Foundations and Trends® in Technology, Information and Operations Management, vol. 1. pp. 1-82.

BoHN, R.E. 2010. How flying got smarter. 2010 IEEE Intelligent Vehicles Symposium, San Diego, CA. pp. 682-687.

Brouillette, E., McGinn, S., Verreault, M., and St-Arnaud, L. 2003. Quantified benefits of automated loading of remote-controlled LHD vehicles in a production environment. CIM Mining Conference and Exhibition, Montreal.

BURGER, D. 2006. Integration of the mining plan in a mining automation system using state- of-the-art technology at De Beers Finsch Mine. Journal of the South African Institute of Mining and Metallurgy, vol. 106, no. 8. pp. 553-559.

Chew, W.B., Leonard-Barton, D., and Bohn, R.E. 1991. Beating Murphy's Law. MIT Sloan Management Review, Spring 1991.

Hoover, H. and Hoover, L.H. (eds). 1950. De Re Metallica. Dover, New York.

Hovis, L. and MouAT, J. 1996. Miners, engineers, and the transformation of work in the western mining industry, 1880-1930. Technology and Culture, vol. 37. pp. 429-456.

Jaikumar, R. 2005. From filing and fitting to flexible manufacturing: a study in the evolution of process control. Foundations and Trends® in Technology, Information and Operations Management, vol. 1. pp. 1-120.
Karmis, M., Hebblewhite, B., de Ruiter, H., Scoble, M., Cedrón, M., and Phillips, H. 2010. Global mining engineering education: past, present, and future, Extracting the Science: A Century of Mining Research. Brune, J. (ed.), Society for Mining, Metallurgy and Exploration, Littleton, CO. pp. 490-499.

LEONARD-BARTON, D. 1992. Core capabilities and core rigidities: a paradox in managing new product development. Strategic Management Journal, vol. 13. pp. 111-125.

Mанмud, A. 2012. Simon Ingersoll. American Society of Mechanical Engineers. https://www.asme.org/engineering-topics/articles/construction-andbuilding/simon-ingersoll

MilleR, C. 2009. Process optimization in mining: The next paradigm shift in productivity gain after mechanization and automation. Proceedings of the 34th International Symposium on the Application of Computers and Operations Research in the Minerals Industries, Vancouver. CIM, Montreal. pp. 439-447.

Mохнам, K. 2004. A hard rock narrow reef mining machine - ARM 1100. Proceedings of the International Platinum Conference 'Platinum Adding Value', Sun City, South Africa, 3-7 October 2004. South African Institute of Mining and Metallurgy, Johannesburg. pp. 207-214.

NoNG, S. 2010. Review of successes and failures of mechanisation trials on platinum mines of the Bushveld Complex. Masters research report, University of the Witwatersrand, Johannesburg.

Nong, S. AND MusingwinI, C. 2011. Successes and failures of mine mechanisation trials on platinum mines of the Bushveld Complex in South Africa. Proceedings of the 20th International Symposium on Mine Planning and Equipment Selection (MPES 2011), Kazakhstan. pp. 942-957.

Paraszczak, J. and Planeta, S. 2001. Man-less underground mining-hurdles on the way to make dreams come true. CIM Annual General Meeting, Québec City, Canda.

SEDGER, J. 1802. Art without Science, or, The Art of Surveying Unshackled with the Terms and Science of Mathematics, Designed for Farmers' boys. Sampson, Chittenden \& Croswell, Hudson, New York.

SEnGE, P.M. 2006. The Fifth Discipline: The Art and Practice of the Learning Organisation. Revised and updated edition. Doubleday, New York.

Swart, C., Miller, F., Corbeil, P.A., Falmagne, V., and St-Arnaud, L. 2002. Vehicle automation in production environments. Journal of the South African Institute of Mining and Metallurgy, vol. 102, no. 3. pp. 139-144.

VAliceK, P., Fourie, F., KRAfFT, G., and SeVEnoAKs, J. 2012. Optimization of mechanised mining layout within Anglo American Platinum. Proceedings of the Fifth International Platinum Conference 'A Catalyst for Change', Sun City, South Africa, 18-20 September 2012. Southern African Institute of Mining and Metallurgy, Johannesburg. pp. 1-35.

VALiDAKIS, V. 2013. Rio's driverless trucks move 100 million tonnes. Mining Australia, 24 April.

WiLson, F. 1972. Labour in the South African Gold Mines, 1911-1969. African Studies Series. Cambridge University Press, Cambridge.

WoMAcK, J.P. and Jones, D.T. 2003. Lean Thinking: Banish Waste and create Wealth in your Corporation, Simon and Schuster. 